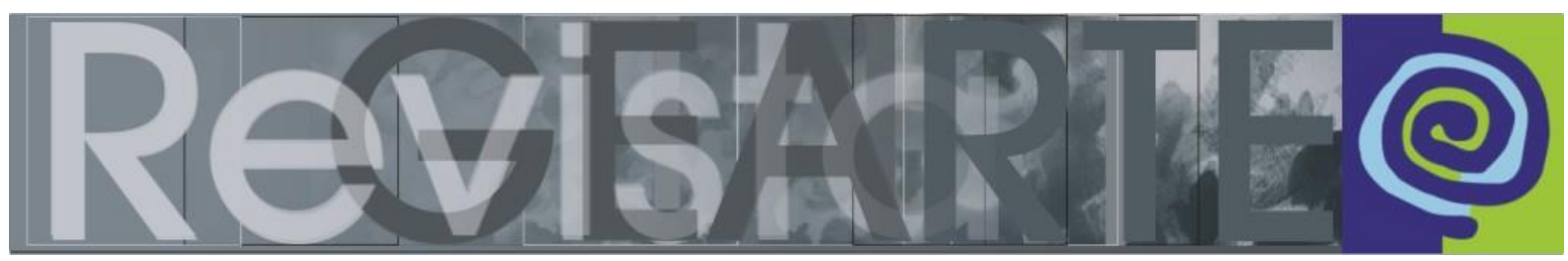

e-ISSN 2357-9854

\title{
Grupos de Estudo, Encontros e Congressos ${ }^{1}$
}

\author{
Ana Mae Barbosa \\ (Universidade de São Paulo — USP/ Universidade Anhembi-Morumbi — UAM, \\ São Paulo/SP, Brasil)
}

Agradeço muitíssimo o convite de minhas colegas do GEARTE, liderado por Analice Dutra Pillar e Maria Helena Rossi, por quem tenho muito afeto e admiração, para escrever neste número da Revista que comemora os 21 anos desse grupo de estudos. No convite feito por Isabel Petry, ela me liberou de regras para escrever o texto e, por isso, ouso me livrar do texto acadêmico e escrever algo mais próximo a ensaio que artigo; mais adequado à conversa livre de protocolo, que adoro ter com a turma do GEARTE, que considero minhas netas, pois são quase todas ex-orientandas de Analice, minha ex-orientanda.

Sou entusiasta da formação de Grupos de Estudos em programas de PósGraduação. Acho mesmo que as experiências com os grupos de estudos nas universidades poderão servir como exemplo para as reformas urgentes que o sistema universitário necessita para se tornar mais democrático e melhor servir à ansiedade de aprendizagem dos jovens de hoje.

Comemorei quando acabaram as cátedras, nome pomposo do sistema ditatorial das universidades que reinava no meu tempo de estudante. Um mandava e todos tinham que obedecer, e eram verdadeiras capitanias hereditárias passando de pai para filho.

1 Neste texto Ana Mae retoma trechos de duas publicações: (a) "Sobre o InSEA Seminar: Building Social Cohesion through Arts Education, Walvis Bay, Namíbia, África", em que ela relata a sua participação no Seminário da InSEA na Mamíbia (Ana Mae Barbosa report), disponível em: http://insea.org/Walvis-Bay-2018. (b) "Ana Mae informa: notícias de Moçambique", publicado por Arte Educação Online - AEOL: http://www.aeol.com.br/2018/12/ana-mae-informa-noticias-democambique.html. (Nota das editoras). 
Mulheres catedráticas eram raras. Pensei que a política de departamentos iria democratizar as universidades. Entretanto na área de Arte/Educação não foi bem assim. Nossa área é desde o início (1973) prioritariamente de mulheres; quando entrava um homem ele já tinha pelo menos $50 \%$ de vantagem sobre as mulheres, poder delegado pelas próprias mulheres, que tinham pouca consciência do quanto eram desqualificadas.

Em muitos casos dois ou três professores combinavam para se alternar no poder do departamento e faziam o que queriam: perseguiam, concediam privilégios, bloqueavam a chance de as mulheres saírem para doutorado ou mestrados. Mas havia outros casos em que reinava a inércia; ninguém queria ser chefe.

Enfim, foi nos grupos de pesquisa que vi a interdisciplinaridade ser praticada e a pesquisa resultar em melhoria da Arte/Educação. A entrada e saída do grupo se dá pela escolha pessoal do aluno e isso os faz mais participantes.

Fiz uma consulta parametrizada nas páginas do CNPq e me tornei consciente de que há 344 grupos de pesquisa em Arte/Educação nas Universidades brasileiras.

O pouco tempo me impede de seguir muitos grupos. Conheço um pouco 0 Grupo de História do Ensino da Arte, de Rejane Coutinho e Rita Bredariolli, o Arte Educação Digital, de Fernanda Pereira da Cunha, na Universidade de Goiânia, o Arte e Pedagogia, de Miriam Celeste, o Arte, Educação e Cultura de Marilda Oliveira, na Universidade Federal de Santa Maria.

Em geral, os grupos escolhem se expressar promovendo congressos e encontros e produzindo publicações.

O GEARTE une os dois processos de apresentação de resultados: organiza encontros excelentes, e sua Revista eu considero atualmente a mais importante em Arte/Educação no Brasil, pois além da qualidade, prima pelo respeito à periodicidade. Já produzi duas revistas e um suplemento de jornal (Jornal da USP) e sei por 
experiência própria que respeito à periodicidade é a coisa mais difícil de se conseguir em uma revista universitária.

Os Encontros e Congressos são fundamentais para o reforço do ego dos Arte/Educadores, em geral mal avaliados pelo sistema, que prioriza a linguagem discursiva e a linguagem científica em detrimento da linguagem presentacional da Arte (Langer,1980). ${ }^{2}$ Fui no começo deste mês a um dos Congressos que mais mobilizaram minhas memórias acerca da história do ensino da Arte no Brasil. Quero compartilhar com vocês minhas impressões sobre o Seminário da International Society for Education through Art na Namíbia, realizado de 29 de outubro a 2 de novembro de 2018. O tema do Seminário foi Building Social Cohesion through Arts Education.

Cheguei a Walvis Bay no dia 28/10/2018 à tarde e tive um impacto com a cidade plantada no deserto. Trata-se de uma cidade urbanisticamente homogênea, toda de casas térreas, do mesmo padrão, embora de arquitetura individual diferente. Minha sensação foi ter chegado a uma cidade democrática com pouca variação de classes sociais e de pequena densidade demográfica. Esta última impressão se confirmou, pois a Namíbia é um dos países com menor densidade demográfica, mas a primeira impressão foi desmentida à medida que conhecia melhor a cidade e descobria algumas poucas casas suntuosas em espaço chegando a três andares. A areia do deserto se impõe e se interliga com a areia da praia. Pistas de concreto das ruas e até do aeroporto são invadidas pela areia e é preciso varrê-las frequentemente. Dunas enormes ornamentam as praias e tempestades de areia assustam os que não têm experiência de viver no deserto.

A comissão cientifica do Seminário - liderada por Christiana Afrikaner, uma arte/educadora muito especial, atenta a cada detalhe da organização e rigorosa com a qualidade do programa - teve 19 representantes da África do Sul, Portugal, Egito,

LANGER, Susanne. Sentimento e forma. São Paulo: Editora Perspectiva, 1980. 
reino Unido, Estados Unidos, Canadá, Espanha, Finlândia, Austrália, Filipinas, Hungria, Turquia e Brasil.

Do Brasil, eu e Miriam Celeste Martins fomos as participantes do Comitê Científico, mas infelizmente só eu compareci ao Seminário, que contou com a colaboração de mais dois professores do Brasil, de cujo trabalho excelente falarei mais adiante.

O Seminário reuniu mais de 200 participantes de todas as regiões do país e mais de 20 convidados estrangeiros, a maior parte deles de países não africanos. Os países com maior número de participantes foram Portugal e Finlândia, com quatro membros cada um.

A estrela do Seminário foi Marc Fritzsche da Universidade de Koblenz-Landau na Alemanha. Ele falou sobre transculturalismo em Arte Educação. Lembrou que a Namíbia já fora dominada pela Alemanha, o que me fez pensar no paradoxo de os povos da Namíbia serem dos mais antigos do mundo, segundo os antropólogos, preservados do comércio de escravos pela inacessibilidade de seu território, mas uma das nações mais jovens. O país foi dominado também pela Inglaterra, da qual herdou a sua língua oficial e pela África do Sul, quando foi obrigado a aprender a língua "africâner". O país foi liberado somente em 1990, embora a cidade de Walvis Bay (um porto importante) tenha continuado na posse da África do Sul até 1994.

Marc Fritzsche resgatou o conceito de transculturalidade de Wolfgang Welsch do fim dos anos 90 , tornando-o muito importante para a arte/educação atual sob a tensão do movimento de refugiados na Europa. A afirmação de que a cultura é um bem móvel, um processo de constante remix, torna complexa a noção de identidade. A noção de terceiro espaço de Homi Bhabha, de remix de Schnurr, e de alteridade de Edward Said, que não são conceitos novos, ganharam profundidade e urgência nos últimos anos, segundo Fritzsche, um jovem muito inteligente, combativo e corajoso. Ele enfrentou o machismo dos mestres de cerimônia do Seminário (coordenadores das apresentações) reclamando em público de um deles, que se dirigia aos 
palestrantes homens chamando-os doutores e pomposamente sublinhando e destacando esse tratamento e às mulheres, também doutoras, chamando-as só pelo nome. Um deles reagiu a um comentário de uma moça muito inteligente, namibiana, diretora da única escola universitária de Arte, que ao acabar o comentário sentou-se dizendo: - Eu não lhe dei permissão para sentar.

Ela muito adequadamente não se levantou, e as outras ao redor dela disseram: - Mas nós demos. O pior é que na apresentação de algumas mulheres, mesmo as doutoras - título que eles valorizavam tanto nos homens, alguns apresentadores (mestres de cerimônia) faziam piada com os títulos da apresentação, deixando as mulheres encabuladas. Um deles fez isso comigo e eu reagi pedindo respeito com os povos indígenas de meu país, dos quais eu ia falar. A piada foi substituir o termo "crafts" do título da minha palestra por "witchcraft" que carrega um histórico de perseguição às mulheres e desqualificação da cultura dos povos autóctones colonizados pelos europeus. Em resposta à minha reação ele não abriu para perguntas do público depois de minha fala, mas não fez falta. O clima de diálogo dominou graças ao espírito participativo dos jovens arte/educadores e artistas da Namíbia e à coordenação democrática de Christiana Afrikaner e de Teresa Eça, da InSEA que está encerrando seu segundo período de presidência com este Seminário na África- uma atitude simbólica.

Diferentemente do Brasil, há uma paridade de gênero na Arte/Educação na Namíbia, enquanto no Brasil temos poucos homens e muitas mulheres. Fora esse incidente fomos muito bem tratados no Seminário. Eu, que estou acostumada a que em países colonizados o tratamento dado aos europeus e americanos do norte é diferenciado para melhor em relação aos convidados de países em desenvolvimento, fiquei muito comovida com o tratamento cuidadoso que todos tiveram comigo, talvez em respeito à minha idade e ao fato de eu ter sido presidente da InSEA.

Me deram um presente muito inusitado e interessante, um prato com minha foto impressa, tirada por eles no Seminário. 
Os assuntos das keynotes foram os mesmos que estão chamando a atenção dos arte/educadores de todo o mundo: problemas de gênero, problemas de decolonização, de diversidade cultural, relação entre design e arte, entre tradição e contemporaneidade, design thinking, criatividade, experiências comunitárias e muita preocupação com o papel das Artes para a liberdade, emancipação, sustentabilidade e crescimento econômico. Este último foi assunto de palestra de Christiana Afrikaner.

O destaque entre os temas foi a importância da diversidade cultural como herança na África nas apresentações de Jorge Gumbe, artista e professor universitário em Angola, e também de Ndasuunje Papa, homem sábio da Namíbia. Um dos problemas discutidos em relação ao ensino da Arte na Namíbia foi o fato de que os artistas ensinam Arte, mas como não são qualificados legalmente para ensinar, ganham pouco como auxiliares de quem tem titulação para o ensino. Alguns conseguem bolsas de estudos para se titularem como professores, mas um deles descortinou uma incoerência governamental semelhante a muitas que temos no Brasil: o governo pagou seu curso, mas se recusou a pagar os exames finais que the concederão o título almejado. Mais uma incoerência: o governo pagou para ele ir ao Seminário. Eles têm uma vantagem sobre nós: não há na Namíbia uma distância tão grande como a que nossas universidades praticam entre a Arte do Povo e a Arte Erudita. Até a Cultura Visual, que em todo o mundo aliviou essa distância, no Brasil se manteve. Aqui a Cultura Visual da década passada se aliou ao quotidiano como poética, e na África, ao Design como produção.

Programas muito interessantes em Universidades foram apresentados, como o de Wearable $\mathrm{Art}^{3}$ de Olusegun Adeniyi, um dinâmico jovem artista e professor da Nigéria; o de formação de professores para a interculturalidade, de Sylvia Esser da Alemanha; o de ensino de inglês como segunda língua e Artes, de Tara Ratnam, da Índia; o de formação de professores para a cidadania, de Alan Richards e Steve Willis, dos Estados Unidos; o de Design Thinking de Gabriella Pataki, da Hungria; o sobre a Metodologia da a/r/tography, através da análise de cartões postais, de Rita Irwin

Arte vestível. (Nota das editoras). 
(Canadá); as excelentes palestras de Teresa Eça, de Portugal, sobre Arte/Educação e desenvolvimento social, e de Pilar Perez, da Espanha, sobre desenvolvimento da criatividade.

Ainda sobre o trabalho em Universidades tivemos o Projeto FADS, apresentado por Kevin Tavin e Mira Tavin, acerca de um consórcio doutoral entre três universidades da Finlândia: a Aalto University School of Arts, Design and Architecture e mais duas universidades da Finlândia, onde o campo de Arte/Educação é considerado campo de pesquisa e estudos e não apenas atividade escolar: a Universidade de Lapland e a Universidade de Jyvaskyla. Os coordenadores dos programas de doutorado em Arte/Educação decidiram que o propósito do consórcio seria criar um fórum de discussão entre 14 alunos de doutorado por eles escolhidos, seis de Aalto, por ser o maior programa doutoral, e quatro de cada uma das outras universidades. O projeto durou quatro anos, houve mobilidade, entrada e saída de estudantes, à medida que terminavam os doutorados. Havia um encontro presencial por ano e os estudos decorriam em grupos, em duplas ou individualmente durante todo o tempo, resultando em um livro que os apresentadores distribuíram ao público, intitulado Experimenting FADS (Finnish Art Education Doctoral Studies).

Os encontros presenciais anuais eram preparados para facilitar a inter-relação pessoal, cada ano em uma das universidades envolvidas e eram previstas sauna, refeições bem planejadas e muita discussão. Cada um desses encontros teve convidados especiais. No primeiro (2014) na Universidade de Lapland foram convidados Jan Jagodzinski, da Universidade de Alberta, no Canadá, e Kerry Thomas e Karen Maras, da Universidade de New South Wales, Austrália. No segundo encontro, em 2015 na Universidade de Jyvaskyla, o convidado foi John Derby, da Universidade de Kansas, EUA; o terceiro, na Universidade de Aalto em 2016, teve como convidado Marc Fritzsche, de quem já falei neste texto. Trata-se de um jovem pesquisador muito talentoso e crítico. As tarefas para serem feitas através da internet eram muitas, entre elas a escolha de textos fundamentais a serem lidos e debatidos, não só sobre as pesquisas de cada um, mas era preciso estar atentos para textos 
apropriados para as pesquisas dos outros componentes do grupo, assim como textos sobre ambientes e abordagens facilitadoras de pesquisa.

A segunda tarefa especialmente depois do segundo encontro era: Mapear pesquisas já terminadas e por fim realizar trocas entre pesquisas. Essa talvez seja a tarefa mais difícil, porém mais produtiva; trabalhar nos sumários de pesquisa uns dos outros, ver com diferentes olhares a mesma pesquisa. Tenho experimentado esse processo no Doutorado em Artes, Design e Tecnologia da Universidade Anhembi Morumbi e ele se revela muito produtivo.Entretanto, o que me fascinou no FADS foi o conjunto de tarefas e o resultado publicado em livro, que mostra o valor do diálogo sistematizado entre doutorandos para revelar o que há de ambíguo, de relevante, de discutível na Arte/Educação de hoje.

Há muito tempo venho sentindo muita necessidade de discutir acerca de orientação doutoral. Quais os melhores caminhos? Como meus colegas orientam? Deveríamos organizar um Grupo de Estudos Interinstitucional sobre o assunto.

Neste projeto, os Tavins ${ }^{4}$ decidem nomear Art-Education com hífen. Não entendi muito bem a razão, mas entre os anos de 70 e 90 eu também assim nomeava a área: Arte-Educação com hífen. No meu caso o fiz, porque queria destacar a cumplicidade, a interdisciplinaridade das duas áreas, Arte e Educação dialogando em pé de igualdade sem a primazia de uma sobre a outra como no caso da nomeação Educação Artística que tornava a Arte mero adjetivo da Educação. Hoje escolho o termo Arte/Educação, porque um linguista disse ser a forma que demonstra mútuo pertencimento.

O livro editado por Kevin Tavis e Mirja Hiltunen 5 é excelente e tem 25 capítulos. O que mais me interessou foi o capítulo 9, de Henrika Ylirisku e Kerry Thomas, sobre Criatividade e Sustentabilidade como prática pedagógica paradoxal na realidade da

4 Kevin Tavin e Mira Tavin, professores da Universidade Aalto, Finlândia. Nota das editoras.

5 Kevin Tavis e Mirja Hiltunen. Experimenting FADS Finnish Art Education Doctoral Studies. Helsinki: Aalto University Publication Series Artes+Design+Architecture, 2017. 
Arte Educação Visual. O paradoxo é que se pensa que os estudantes permanecem comprometidos com seu processo criador, embora desejando a intervenção do professor. Entretanto, os autores verificaram que os estudantes ficavam felizes em aceitar o que o professor propunha para o trabalho deles, sacrificando suas próprias intenções. ${ }^{6}$

Meu interesse foi maior por esse texto, porque estou pesquisando sobre a volta da criatividade em Arte/Educação. Nos anos 70 e 80 os estudos sobre criatividade valorizavam principalmente a fluência e a originalidade. Hoje o interesse sobre a criatividade volta, depois de uns 15 anos de apagamento dessa palavra no vocabulário pedagógico, valorizando mais a flexibilidade e a reelaboração. Estou pesquisando essa reelaboração, a criatividade coletiva e a criatividade e o ativismo político em Arte.

Uma parte importante desse Seminário na Namíbia foi a planejada relação da teoria com a prática em bem organizados workshops. Houve oficinas para os membros do Seminário e oficinas nas escolas de crianças e adolescentes da rede pública, dada por artistas ou professores de universidades estrangeiras. Esse foi o caso do trabalho de Paulo Cesar da Silva Teles, da UNICAMP, Brasil, e Rosana Bernardo, da Escola Waldorf de Campinas. Eles chegaram a Walvis Bay uma semana antes do Seminário e trabalharam numa escola. Apresentaram o resultado do trabalho de fotografias feitas por crianças de 9 a 14 anos, entrevistas em áudio com elas e domínio de tecnologias contemporâneas. $O$ trabalho se corporificou numa escultura de uma palmeira de papelão e outros suportes com dois sensores eletrônicos: um de som e outro de imagem. No primeiro, ao nos aproximarmos, ouvíamos as falas dos adolescentes sobre suas vidas, seus objetivos e suas expectativas. Do outro lado, o sensor de imagens, ao nos aproximarmos, projetava as fotografias produzidas por eles. ${ }^{7}$ Os dois

6 YLIRISKU, Henrika; THOMAS, Kerry. Creativity and Sustentability as Paradoxical Pedagogic Practices in the Reality of Visual Art Education. In: TAVIS, Kevin; HILTUNEN, Mirja. Experimenting FADS Finnish Art Education Doctoral Studies. Helsinki: Aalto University Publication, Series Artes+Design+Architecture. 2017. p. 94-101.

7 TELES, Paulo Cesar da Silva; BERNARDO, Rosana; NETO, Gabriel. The Wishing Tree. UNICAMP, Brasil. Abstract: Uma estrutura em forma de árvore é construída a partir de lixo e anexado com sensores de proximidade. De acordo com o movimento das pessoas ao redor disso, os desejos 
professores formaram uma dupla de ação educacional muito positiva. Paulo, canalizador de teorias na prática, inteligente e inquieto, estimulou as falas e imagens produzidas pelos alunos, e Rosana, um ser aglutinador, estimulou a coesão com sua presença calma, mas produtiva, que põe ordem em qualquer caos. No sábado, dia 3 de novembro à noite, houve um encontro de Arte de uma escola privada, para o qual fui convidada por J. Marthin, um dos diretores da Society for Arts Education in Namíbia (SAEN), responsável pelo Seminário, no qual a instalação interativa dos brasileiros foi não só apresentada novamente, Mas o centro das discussões sobre ecologia, novas tecnologias e fusão de tradição e alta tecnologia.

Outro workshop com crianças em escola pública foi o de Sasha Sicurella, artista canadense da instituição ARTOMI de New York (education@artomi.org), dirigida ao desenvolvimento da criatividade e exploração da identidade cultural através da arte, fotografia, cinema e autorretrato ao redor do mundo.

Muitos corais infantis, de adolescentes e de adultos de alta qualidade se apresentaram nos intervalos das palestras e workshops me fazendo crer que a Música é a Arte mais atuante nas escolas da Namíbia.

Samia El Sheikh, do Egito, membro do Comitê Regional da África na InSEA, deu divulgação aos valores da União Africana - que enviou como delegada para o Seminário Angela Martins, diretora de Políticas Culturais, uma determinada e inteligente moçambicana.

O Seminário mobilizou as pessoas ligadas ao poder público da Namíbia, que falaram nas cerimônias de abertura e fechamento, como o Governador da Região de Erongo, o prefeito de Walvis Bay, diretora de Educação e vários honoráveis de

expressados por estudantes Namime de 9 a 14 anos são acionados em uma projeção de tela e altofalante de som. Esta instalação interativa sensorial sem toque é o resultado de um workshop que teve lugar na Inara Primary School em Walvis Bay uma semana antes. Ela combina uma fusão de artesanato, de alta tecnologia tradicional (desenho, colagem, pintura, assemblage) e expressões de mídia. Essa escultura, uma vez que é feita por professores e estudantes daquela escola com material reciclado, promove discussões ecológicas, anticonsumistas e éticas por meio de um conjunto transcultural de atividades. (Programa do seminário, p. 14). 
diversos conselhos de Estado (Região). A presença dos políticos que têm poder para mudar é uma esperança que valorizem mais ainda a Arte na Educação, porque Arte/Educação é um direito humano.

Não fiquei só na Namíbia. A África me fascina, por ter sobrevivido culturalmente apesar dos desmandos dos colonizadores.

\section{Notícias de Moçambique}

Ao ser convidada para o Seminário da InSEA, Building Social Cohesion through Arts Education, na Namíbia, avisei que estaria na África no começo de novembro, ao professor Lourenço Cossa, de Moçambique, de quem examinei uma excelente tese de doutorado, orientada por Analice Dutra Pillar na UFGRS. Ele imediatamente me convidou para dar uma palestra na Universidade Pedagógica, na Escola Superior Técnica, Departamento de Desenho e Construção, no qual é o único professor doutor - responsabilidade enorme para meu colega moçambicano. Sei disso por experiência própria, pois por quase dez anos fui a única doutora em Arte/Educação no Brasil. Depois disso, nos desenvolvemos muito rapidamente graças à criação de linhas de pesquisas nas Pós-Graduações em Artes e Educação.

Os moçambicanos foram excelentes hospedeiros. Reuniram mais de 200 professores para ouvir minha palestra, que eles intitularam de Ensino da Educação Visual: Artes e formação de professores. Lá em Moçambique o nome da disciplina de Artes no currículo do ensino fundamental e médio é Educação Visual. Os burocratas da educação estão querendo retirá-la do ensino médio, como o governo Temer fez no Brasil. Com eu já havia notado no Seminário da InSEA na Namíbia, os homens também em Moçambique são a maioria dos professores de Arte, diferentemente do Brasil, onde esta área é maciçamente feminina.

A mesa de abertura de minha palestra foi composta de pessoas importantes na Universidade. Também convidaram Sílvia Bragança, arte/educadora, professora de História da Arte e curadora. Trabalhamos juntas muitos anos no Conselho Mundial da InSEA, no qual ela representava a África e eu, a América Latina (1984 a 1994). Silvia 
é viúva de Aquino de Bragança, um dos heróis libertadores de Moçambique, que morreu no atentado ao Presidente Samora Machel. Aquino de Bragança era jornalista e intelectual, criador e diretor do Centro de Estudos Africanos da Universidade Eduardo Mondlane. Visitei com Silvia esta Universidade, onde ela iniciou em Moçambique a área de Educação Visual.

Silvia é extremamente respeitada e querida por toda a intelectualidade do país que adotou, pois nasceu em Goa, na Índia, em 1937.

No dia da palestra, 6 de novembro, fui entrevistada por TV e Rádio.

O auditório produziu um excelente e quase interminável diálogo depois de minha palestra. As perguntas que se seguiram eram oportunas e inteligentes, demostrando conhecimento de meus livros, especialmente da Abordagem Triangular. São alunos, professores e artistas atualizados nas pesquisas sobre Ensino da Arte; o que Ihes falta é a ampliação das estruturas institucionais e criação de mestrados e doutorados. No dia seguinte tive um encontro com o grupo com o qual Lourenço trabalha. Estão se titulando fora do país. Mestre Rangel Manjate é um teórico complexo, designer gráfico e professor em Educação Visual; Marcos Muthewuye, um escultor muito talentoso, e José Hoguane, que está terminando o doutorado em Portugal, é um excelente conhecedor de políticas culturais e coordenador dinâmico de um departamento.

À tarde, visitei com Lourenço as instituições culturais de Maputo, como museus, centros culturais, galerias de arte e o Centro de Artesanato, onde vi excelentes trabalhos.

A Fundação Fernando Leite Couto, criada em 2015 em homenagem ao poeta falecido em 2013, irmão de Mia Couto, foi talvez a visita mais agradável. Conversamos com pessoas que o estavam visitando, um artista local, um garçom conhecedor de Arte, todos entusiasmados pelo trabalho em literatura e artes visuais que a Fundação faz. Naquele dia, 7 de novembro, estava sendo inaugurada uma exposição de Manuel Bata, intitulada "Os sentimentos das mãos", e na noite anterior havia sido lançado um 
livro para crianças, de Mia Couto. Em três anos a Fundação criada pela família Couto já se tornou um fator de mudança, pois vem respeitando seu lema: "Fazer junto com os outros".

Vendo a ação multiplicadora de Lourenço Cossa em seu departamento reforçou-se minha convicção de que os programas de bolsas de estudos do Brasil para nossos colegas africanos são essenciais para que conheçamos as culturas uns dos outros e as reforcemos mutuamente.

Um membro do Gearte está transculturando o grupo em Moçambique. Portanto o GEARTE tem maioridade e internacionalidade.

\section{Ana Mae Barbosa}

Possui graduação em Direito pela Universidade Federal de Pernambuco (1960), mestrado em Art Education pela Southern Connecticut State College (1974) e doutorado em Humanistic Education pela Boston University (1978). Atualmente é Professora Titular aposentada da Universidade de São Paulo e professora da Universidade Anhembi Morumbi. Foi presidente da International Society for Education through Art (InSEA), da Associação Nacional de Pesquisadores em Artes Plásticas (ANPAP) e diretora do Museu de Arte Contemporânea da USP. Tem livros e artigos publicados em diversos países. Tem experiência na área de Artes, com ênfase em Arte/Educação, atuando principalmente nos seguintes temas: Ensino da Arte e contextos metodológicos, História do Ensino da Arte e do Desenho, Ensino do Design, Administração de Arte, Multiculturalidade, Estudos de Museus de Arte e Estudos Visuais.

E-mail - anamaebarbosa@gmail.com

Currículo - http://lattes.cnpq.br/1650414096296319

Recebido em 11 de janeiro de 2019

Aceito em 15 de fevereiro de 2019 